\title{
Evaluation of Anosognosia in Alzheimer's Disease Using the Symptoms of Early Dementia-11 Questionnaire (SED-11Q)
}

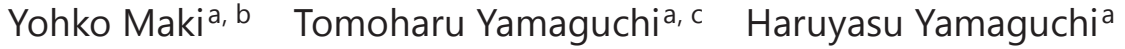 \\ ${ }^{a}$ Gunma University Graduate School of Health Sciences, ${ }^{b}$ Geriatrics Research Institute and \\ Hospital, and 'Department of Rehabilitation, Gunma University of Health and Welfare, \\ Maebashi, Japan
}

\section{Key Words}

Anosognosia - Dementia - Alzheimer's disease - Behavioral and psychological symptoms of dementia - Metacognition - Caregiver burden - Dementia care · Mild cognitive impairment . Screening test

\section{Abstract}

Aims: The objective is to propose a brief method to evaluate anosognosia in Alzheimer's disease (AD) using the Symptoms of Early Dementia-11 Questionnaire (SED-11Q), a short informant-based screening questionnaire for identifying dementia. Methods: The participants were 107 elderly individuals: 13 with a Clinical Dementia Rating (CDR) of 0.5, 73 with mild AD of CDR 1 , and 21 with moderate AD of CDR 2. The patients and caregivers answered the SED$11 \mathrm{Q}$ independently, and the degree of discrepancy indicated the severity of anosognosia. $\boldsymbol{R e}$ sults: The scores were as follows: caregiver scores were $2.46 \pm 1.85$ (mean \pm SD) in CDR 0.5, $6.36 \pm 3.02$ in CDR 1, and $9.00 \pm 1.14$ in CDR 2; patient scores were $2.00 \pm 1.78,2.55 \pm 2.33$, and $1.33 \pm 2.46$, respectively. Discrepancy was $0.46 \pm 1.61,3.81 \pm 3.95$, and $7.67 \pm 2.87$, respectively, and the caregiver assessments were significantly higher than the patient assessments in CDR 1 and CDR 2 ( $p<0.001$ in both groups). The SED-11Q for anosognosia was validated with the standardized Anosognosia Questionnaire for Dementia (AD-Q). The caregiver scores were moderately correlated with behavioral and psychological symptoms of dementia scores $(r=0.524)$, and the patient scores were moderately correlated with depression scores $(r=0.561)$. Conclusion: The SED-11Q serves a dual purpose: caregiver assessment is useful for the screening of dementia, and any discrepancy between the patient and the caregiver assessment is considered as an indication of the severity of anosognosia; this can be informative for caregivers and essential for successful care. 
Maki et al.: Evaluation of Anosognosia in Alzheimer's Disease Using the Symptoms of Early Dementia-11 Questionnaire (SED-11Q)

\section{Introduction}

A deficit in the level of self-awareness of disease, anosognosia, has been recognized as one of the typical symptoms in Alzheimer's disease (AD), and self-awareness gradually deteriorates as the disease progresses $[1,2]$. Patients with anosognosia have difficulties in self-monitoring from the perspective of a third person and tend to overestimate their abilities [3].

Overconfidence due to diminished insight $[4,5]$ has a negative impact on the caregiver burden over and above the cognitive deficits and functional impairments [6]. Coupled with the care burden, the discrepancy between the caregiver's and the patient's evaluation of deficits can result in a breakdown of the relationship, and this could lead to behavioral and psychological symptoms of dementia (BPSD) [7].

For example, agitated and aggressive behaviors may be triggered by negatively affected interpersonal relationships between the patients and the caregivers. It is often the case that patients with anosognosia refuse to acknowledge their deficits and failures. If the caregivers pointed out their failures, the patients might feel that they are being unreasonably criticized, because they firmly believe that they are right. Due to a decline in their capacity to frame their thoughts and control their emotional states, they may easily be upset and resort to physical aggression. To prevent and/or soothe agitation and aggression, evidence increasingly supports psychological interventions as a first-line management strategy [8]. Caregivers who strive to understand the intention behind patients' behaviors could be more successful at reducing BPSD than caregivers who have merely physical and custodial roles, and patients who feel appreciated and respected by their caregivers may be less likely to resort to inappropriate behaviors [9].

As outlined above, it is beneficial for caregivers to understand how the patients feel and to perceive their deficits from their perspective. Thus, the evaluation of anosognosia is an essential requirement for successful care [10].

Anosognosia can be assessed as follows. The patients and caregivers independently answer the same questions about how the patient is functioning. The caregiver assessment is taken to be the objective standard, and any discrepancy between the patient and the caregiver assessment is considered as an indication of the severity of anosognosia [11]. In the present study, we describe a brief method to evaluate anosognosia in AD using the Symptoms of Early Dementia-11 Questionnaire (SED-11Q) [12]. The SED-11Q is a short informant-based screening questionnaire which is used to identify dementia in both clinical and communitybased settings and to detect undiagnosed $\mathrm{AD}$ and other types of dementia early. As deficits caused by dementia are manifested in various aspects, the SED-11Q asks questions about 11 early signs of memory deficits, difficulties with the activities of daily life, and changes in social interaction and personality. TheSED-11Q reliably differentiates nondemented from demented individuals. In the clinical setting with physicians and other medical staff, the statistically optimal cutoff value of $2 / 3$, which indicates a sensitivity of 0.841 and a specificity of 0.901 , can be applied. In the community setting, where community-dwelling elderly individuals are screened for dementia, a cutoff value of $3 / 4$, which indicates a sensitivity of 0.764 and a specificity of 0.963 , is recommended because of their high specificity and positive predictive values. In addition to the 11 questions, the SED-11Q has 2 further questions about delusions and illusions, and medical consultation is recommended whenever delusions or illusions are detected.

The SED-11Q is easily administered within 5 min and is both patient- and caregiverfriendly, since only 11 questions with yes/no responses need to be answered. The results can be informative for caregivers and provide an opportunity for them to reconsider their relationships with patients and improve their care giving. 
Maki et al.: Evaluation of Anosognosia in Alzheimer's Disease Using the Symptoms of Early Dementia-11 Questionnaire (SED-11Q)

\section{Methods}

The participants were 107 elderly individuals: 13 with amnestic mild cognitive impairment (MCI) in a Clinical Dementia Rating (CDR) [13] of 0.5, 73 with mild dementia with AD of CDR 1 , and 21 with moderate AD of CDR 2. Demented individuals were outpatients who were diagnosed according to criteria for dementia diseases such as NINCDS-ADRDA [14]. MCI was diagnosed according to the recommendations of the report of the International Working Group on Mild Cognitive Impairment [15]. CDR 0.5 was regarded as MCI, although a different classification was proposed whereby CDR 0.5 encompasses both mild and earlier dementia [16] or corresponds with very mild dementia [17]. Depression was an exclusion criterion for $\mathrm{MCI}$ in CDR 0.5. Informants were restricted to caregivers who were family members and who knew the patient's activities of daily life. These informants had normal cognitive abilities without depression, and both caregivers and patients were without psychiatric diseases, delirium, or verbal incomprehension including aphasia.

The informants were required to fill out the SED-11Q which consists of 11 questions regarding the following issues: repetitive talking, difficulties in context understanding, indifference to clothing, difficulties in cleaning up, forgetting one of two items, difficulties in selfmedication, time-consuming behavior, difficulties in planning, difficulties in understanding complex topics, loss of interest, and becoming irritable and suspicious. They were requested to respond with a yes or a no (yes $=1$ point) to each item. Two additional questions about delusion and illusion were not included in the SED-11Q for patients (SED-11Qp) (fig. 1); thus, these 2 questions were excluded from the difference calculation.

Concerning BPSD, the participants were required to complete the Japanese version of the Dementia Behavior Disturbance scale (DBD) [18]. The DBD consists of 28 items including the most common symptoms such as repetitive questions, losing or hiding things, lack of interest in daily activities, nocturnal wakefulness, unwarranted accusations, excessive daytime sleeping, and pacing. Scores range from 0 to 84 and a high score indicates greater BPSD.

The patients were required to complete the SED-11Qp to evaluate their awareness of deficits. The depressive tendency was evaluated using the Japanese version of the Geriatric Depression Scale (GDS) [19]. The GDS is a self-rating depression screening scale for elderly populations that asks questions about 15 items. Scores of $0-4$ indicate no depressive tendency, scores of 5-9 indicate mild depressive tendency, and scores of 10-15 indicate severe depressive tendency.

For external validation of the SED-11Q, we used the standardized questionnaire of anosognosia, the Japanese version of the Anosognosia Questionnaire for Dementia (AQ-D) $[20,21]$, which contains questions about the awareness of deficits in intellectual functioning (22 items), and mood and behavior domains (8 items). Each item of the AQ-D was evaluated on a $0-3$ scale: never ( 0 points), sometimes ( 1 point), usually ( 2 points), or always ( 3 points). Lower scores of the patients indicated deficits of awareness in comparison with those of the caregivers.

Summed scores of SED-11Q were compared among the CDR groups using $2 \times 3$ repeated measures ANOVA (the patients and their caregivers in pairs, and 3 groups according to CDR). For external validation, the correlation was evaluated with SED-11Q and AQ-D scores. Considering ceiling effects in CDR 2, analyses of subitems and correlation of SED-11Q with GDS and DBD were conducted with patients only in CDR 1 . All analyses were conducted using the Japanese version of SPSS for Windows version 19.0 (IBM Corp., New York, N.Y., USA). The significance was set as $\mathrm{p}<0.05$. The Ethics Board of the Gunma University School of Health Sciences approved all procedures (No. 21-27), and written informed consent was obtained from the participants. 
Maki et al.: Evaluation of Anosognosia in Alzheimer's Disease Using the Symptoms of

\title{
a Symptoms of Early Dementia-11 Questionnaire (SED-11Q)
}

\author{
Date (MM/DD/YYYY) \\ Patient Name:

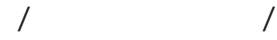 \\ Respondent Name: \\ Respondent-completed / Interview by Name: \\ How has the patient's daily life been for the last month? \\ Please answer the following questions by circling the appropriate \\ responses (Exclude any difficulties caused by physical issues, e.g., pain). \\ Please ask for any help if needed.
}

Patient ID:

Relationship:

\begin{tabular}{|c|c|c|c|}
\hline \multirow[t]{2}{*}{$\mathrm{He} /$ she talks and asks about the same things repeatedly. } & \multirow[t]{2}{*}{ YES } & \multirow[t]{2}{*}{ NO } & \multirow{2}{*}{$\begin{array}{l}\text { N/A } \\
\text { Don't know }\end{array}$} \\
\hline & & & \\
\hline $\begin{array}{l}\mathrm{He} / \text { she has become unable to understand the context of facts. } \\
\mathrm{He} / \text { she has become indifferent about clothing and other personal }\end{array}$ & YES & NO & $\mathrm{N} / \mathrm{A}$ \\
\hline concerns. & YES & NO & $\mathrm{N} / \mathrm{A}$ \\
\hline $\begin{array}{l}\text { He/she has begun to forget to turn off the faucet and/or close the door, } \\
\text { and/or has become unable to clean up properly. }\end{array}$ & YES & NO & $\mathrm{N} / \mathrm{A}$ \\
\hline When doing two things at the same time, he/she forgets one of them. & YES & NO & N/A \\
\hline $\begin{array}{l}\mathrm{He} / \text { she has become unable to take medication under proper management. } \\
\mathrm{He} / \text { she has begun to take a longer time to do work (e.g., household chores) }\end{array}$ & YES & NO & N/A \\
\hline which could be done quickly before. & YYS & NO & $\mathrm{N} / \mathrm{A}$ \\
\hline $\mathrm{He}$ /she has become unable to make a plan. & YES & NO & $\mathrm{N} / \mathrm{A}$ \\
\hline $\mathrm{He} /$ she cannot understand complex topics. & YES & NO & $\mathrm{N} / \mathrm{A}$ \\
\hline $\mathrm{He} /$ she has become less interested and willing, and stopped hobbies, etc. & YES & NO & $\mathrm{N} / \mathrm{A}$ \\
\hline $\mathrm{He} /$ she has become more irritable and suspicious than before. & YES & NO & N/A \\
\hline TOTAL SED-11Q SCORE & & & \\
\hline $\begin{array}{l}\mathrm{He} \text { /she has delusions, e.g., claims to have had valuables s } \\
\mathrm{He} \text { /she has illusions, e.g., sees something that isn't there. }\end{array}$ & $\begin{array}{l}\text { YES } \\
\text { YES }\end{array}$ & $\begin{array}{l}\text { NO } \\
\text { NO }\end{array}$ & $\begin{array}{l}\text { N/A } \\
\text { N/A }\end{array}$ \\
\hline
\end{tabular}

If the answer is 'yes' to either of these 2 questions, then a more

comprehensive medical consultation is recommended.

1

(For legend see next page.)

\section{Results}

Demographic data are shown in table 1 . A higher score indicates more severe symptoms. The caregiver assessments were $2.46 \pm 1.85$ (mean \pm SD) in CDR 0.5, 6.36 \pm 3.02 in CDR 1 , and $9.00 \pm 1.14$ in CDR 2. Scores in CDR 2 were significantly higher than those in CDR 1 , and those in CDR 1 were significantly higher than those in CDR 0.5 . The patient assessments were 2.00 \pm 1.78 in CDR 0.5, $2.55 \pm 2.33$ in CDR 1 , and $1.33 \pm 2.46$ in CDR 2; there was no significant difference among the 3 groups. The discrepancy was $0.46 \pm 1.61$ in CDR $0.5,3.81 \pm 3.95$ in CDR 1, and $7.67 \pm 2.87$ in CDR 2 (table 1). Concerning discrepancy, the caregiver assessment was significantly higher than the patient assessment in the CDR 1 and CDR 2 groups $(\mathrm{p}<0.001$ in both groups), but not in the CDR 0.5 group $(p=0.641)$. The discrepancy was significantly different among the groups $(\mathrm{p}<0.001$, fig. 2$)$.

A correlation of the SED-11Q and the AQ-D was conducted with 43 pairs, and the scores of the evaluation using the SED-11Q were significantly correlated with those using the AQ-D: patient scores $(r=0.549, p<0.001)$, caregiver scores $(r=0.646, p<0.001)$, and discrepancy scores $(r=0.669, \mathrm{p}<0.001)$.

The correlation coefficients with DBD were $r=0.132(\mathrm{p}=0.236)$ in patient scores, $\mathrm{r}=$ $0.524(\mathrm{p}<0.001)$ in caregiver scores, and $r=0.349(\mathrm{p}=0.001)$ in discrepancy scores. The correlation coefficients with GDS were $r=0.561(p<0.001)$ in patient scores, $r=-0.092(p=$ 


\section{b How do you feel?}

Date (MM/DD/YYYY)

Name:
ID:

Respondent-completed / Interview by Name:

How has your daily life been for the last month?

Please answer the following questions by circling the appropriate responses (Exclude any difficulties caused by physical issues, e.g., pain).

Please ask for any help if needed.

You talk and ask about the same thins repeatedly.

YES NO N/A

YES NO N/A

You have become unable to understand the context of facts.

You have become indifferent about clothing and other personal concerns.

You have begun to forget to turn off the faucet and/or close the door, and/or have become unable to clean up properly.

When doing two things at the same time, you forget one of them.

You have become unable to take medication under proper management. YES

You have begun to take a longer time to do work (e.g., household chores), which could be done quickly before.

You have become unable to make a plan.

You cannot understand complex topics.

You have become less interested and willing, and stopped hobbies, etc.

You have become more irritable and suspicious than before.
YES NO N/A

YES NO N/A

YES NO N/A

NO N/A

YES NO N/A

YES NO N/A

YES NO N/A

YES NO N/A

YES NO N/A

\section{TOTAL SED-11Q SCORE}

Fig. 1. SED-11Q (a) and SED-11Qp (b). The SED-11Qp asks the same questions as the SED-11Q. However, the title was changed to avoid using the word 'dementia'. 'Patient Name' and 'Patient ID' were changed to 'Name' and 'ID'. Two additional questions about delusions and illusions in SED-11Q were not included in the SED11Qp. The questionnaires can be completed by interview.

Table 1. Demographic data

\begin{tabular}{lccc}
\hline & $\begin{array}{l}\text { CDR 0.5 } \\
(\mathrm{n}=13)\end{array}$ & $\begin{array}{l}\text { CDR 1 } \\
(\mathrm{n}=73)\end{array}$ & $\begin{array}{l}\text { CDR 2 } \\
(\mathrm{n}=21)\end{array}$ \\
\hline Age, years & $73.4 \pm 5.3$ & $80.3 \pm 5.9$ & $83.4 \pm 5.9$ \\
Gender (male/female) & $8 / 5$ & $26 / 47$ & $7 / 14$ \\
MMSE & $27.4 \pm 1.7$ & $20.0 \pm 4.4$ & $13.6 \pm 4.8$ \\
SED-11Q & & & \\
$\quad$ Caregivers & $2.46 \pm 1.85$ & $6.36 \pm 3.02$ & $9.00 \pm 1.14$ \\
$\quad$ Patients & $2.00 \pm 1.78$ & $2.55 \pm 2.33$ & $1.33 \pm 2.46$ \\
$\quad$ Discrepancy & $0.46 \pm 1.61$ & $3.81 \pm 3.95$ & $7.67 \pm 2.87$ \\
\hline
\end{tabular}

With the exception of gender (number of patients) values represent mean \pm SD. Values in parentheses represent the number of patients in the groups. The ages were significantly different between the groups $(\mathrm{p}<0.001)$. 


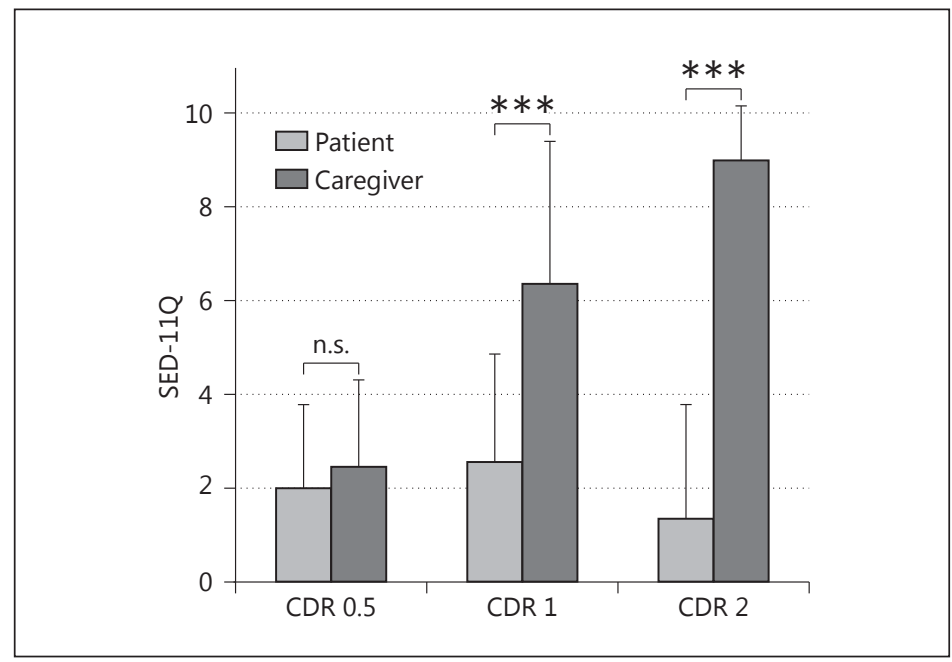

Fig. 2. Scores of the SED-11Q. A higher score indicates more severe symptoms. Caregiver assessments, which were regarded as the objective standard of patient dysfunction, increased as the disease progressed, whereas patient assessments were not significantly different among the 3 stages. The discrepancy between caregiver and patient scores indicated the severity of anosognosia. In the CDR 0.5 group, there was no significant difference, which suggested that patients retain self-awareness of the disease. In the CDR 1 and 2 groups, the caregiver assessment was significantly higher than the patient assessment, and the discrepancy was larger in the CDR 2 than in the CDR 1 group. ${ }^{* * *} \mathrm{p}<0.001$.

$0.538)$ in caregiver scores, and $r=-0.401(p=0.005)$ in discrepancy scores. An analysis of subitems was conducted with patients in CDR 1 (fig. 3). Figure 3 shows the ratio of each item in CDR 1: both caregiver and patient aware, caregiver aware and patient unaware (anosognosia or hyponosognosia), caregiver unaware and patient aware (hypernosognosia), and both caregiver and patient unaware. The ratios of cases where patients were aware and caregivers were unaware were $9.6 \%$ in difficulties in cleaning up, $12.3 \%$ in forgetting one of two items, and $12.3 \%$ in time-consuming behavior.

\section{Discussion}

The present study showed that a short questionnaire based upon SED-11Q could reliably evaluate anosognosia in AD. This shows that the SED-11Q can serve a dual purpose in the clinical setting: caregiver assessment is useful for early detection of undiagnosed dementia, and the discrepancy between caregiver and patient assessment indicates the severity of anosognosia.

Anosognosia increases in severity with disease progression, as reported in previous studies $[1,2,10]$. In CDR 0.5, the discrepancy of the assessment between patient and caregiver was controversial [22-24], but this discrepancy was not significant in the current study.

Regarding BPSD, caregiver scores were moderately correlated with BPSD scores measured by the DBD. The correlations suggested that BPSD would be more severe as deficits become prominent in multiple domains in CDR 1. It is pointless to alert patients to their deficits, because decreased self-awareness of their deficits is one of the characteristic symptoms related to degeneration in AD. As previous studies suggested, caregivers who try to understand the meaning behind patients' words and action could be more successful at 
Maki et al.: Evaluation of Anosognosia in Alzheimer's Disease Using the Symptoms of Early Dementia-11 Questionnaire (SED-11Q)

Fig. 3. The ratio (percentile) is shown for each item in CDR 1: both caregiver and patient aware $(\mathrm{Cg}+\mathrm{Pt}+)$, caregiver aware and patient unaware (anosognosia or hyponosognosia, Cg+ Pt-), caregiver unaware and patient aware (hypernosognosia, $\mathrm{Cg}-\mathrm{Pt}+$ ), and both caregiver and patient unaware (Cg- Pt-). The ratios of cases in which patients were aware and caregivers were unaware were $9.6 \%$ in difficulties in cleaning up, $12.3 \%$ in forgetting one of two items, and $12.3 \%$ in timeconsuming behavior.

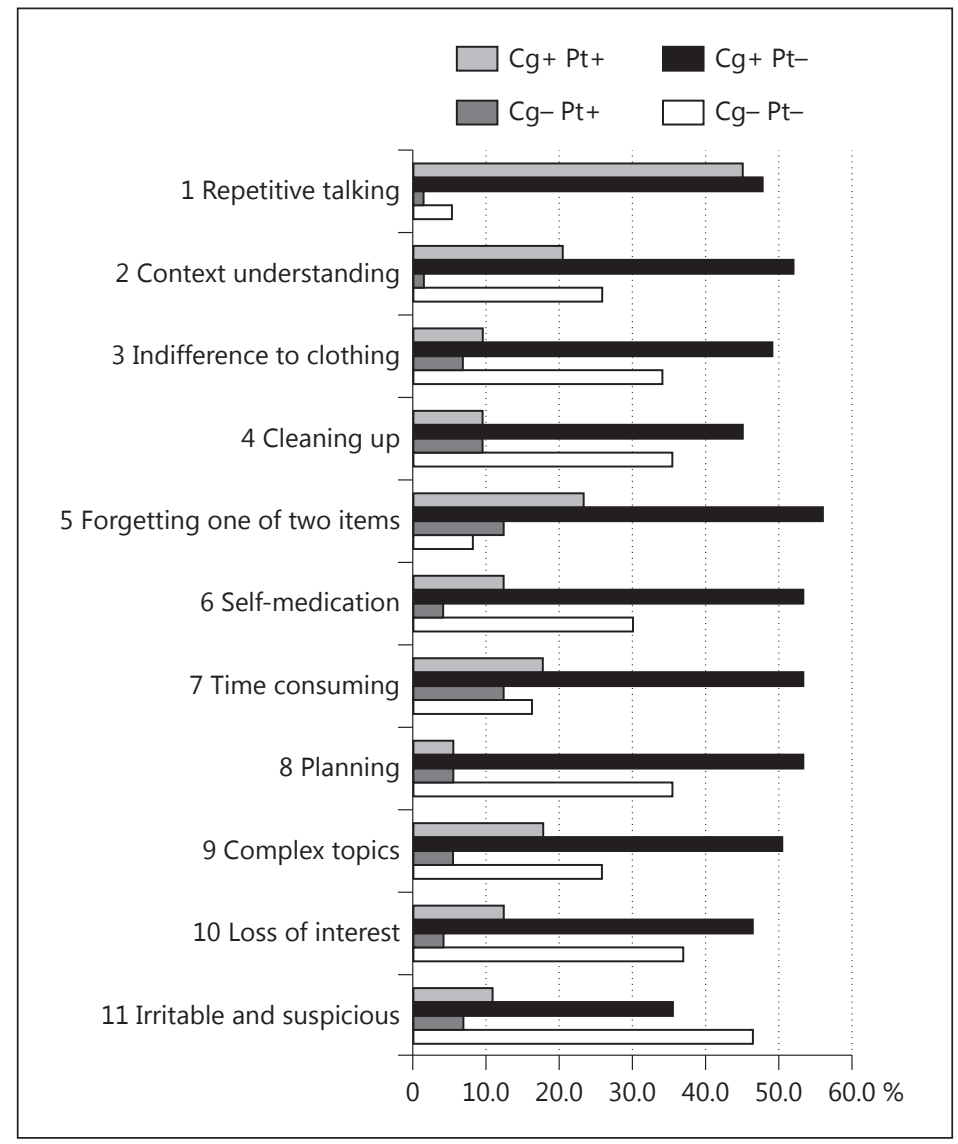

reducing BPSD; it is an efficient strategy for caregivers to accept the patients' perspectives, even when their behaviors are problematical $[9,25]$.

The SED-11Q serves as a coping resource to encourage families to understand and accept the patients' perspectives. A visual comparison of what was written by both patients and caregivers can have a positive effect on caregivers; many caregivers renewed their awareness regarding patients' thoughts and feelings, when they saw the completed questionnaire of the patients. Caregivers are also expected to notice that patients might feel distressed by the selfawareness of deficits even though the awareness is partial and insufficient. The depressive mood in patients measured by GDS was modestly correlated with patient assessments, agreeing with previous studies which reported that patient complaints of cognitive deficits are correlated with depressive symptoms rather than with cognitive decline [5, 26, 27]. On counseling, each item should be considered respectively. There could be some activities or functions that patients worry about more than caregivers, hypernosognosia, although generally patients had partial and/or insufficient awareness of their deficits. As shown in figure 3 , there were certain deficits of hypernosognosia that were noticed by the patients but not by the caregivers: $9.6 \%$ in difficulties in cleaning up, $12.3 \%$ in forgetting one of two items, and $12.3 \%$ in time-consuming behavior. It becomes difficult for those in CDR 1 to function independently, even if compensatory strategies are employed. A deficit in cleaning up is a typical behavior of demented individuals with attentional decline. Forgetting one of two items and time-consuming behaviors are characteristic in those with difficulties in executive function. Such hypernosognosia should be carefully examined to understand what the patients feel distressed about. If the caregivers feel empathy for the patients' distress, the patients 
Maki et al.: Evaluation of Anosognosia in Alzheimer's Disease Using the Symptoms of Early Dementia-11 Questionnaire (SED-11Q)

would feel appreciated and respected and they might be less likely to act out their frustrations in an inappropriate manner.

Nondemented subjects with depression tend to have higher marks than their caregivers. For example, one typical subject with depression, who is not included in the current study, had a score of 7 of 11, while his spouse had a score of 2 of 11 (GDS 11/15, which suggested severe depression; MMSE 29/30). The SED-11Q could serve as a screening tool to differentiate between dementia and depression, and we are now collecting more data for further analysis.

In the present study, the subjects were restricted to AD patients. However, in practical use the SED-11Q can be applied to patients with other types of dementia for the evaluation of anosognosia. In our outpatient setting, we counsel caregivers using the SED-11Q, and interventional effects will be reported.

\section{Acknowledgement}

The authors thank all the study participants, Dr. Masamitsu Takatama, Geriatrics Research Institute and Hospital, Maebashi, and Rumi Shinohara and Yuko Tsunoda, Gunma University, Maebashi, for their support. Dr. H. Yamaguchi was supported by a Grant-in-Aid for Scientific Research from the Ministry of Education, Science, Sports, Culture, and Technology, Japan (23300197) and a Grant-in-Aid for Scientific Research (H24-Ninchisho-Ippan-002, H25-Ninchisho-Ippan-008) from the Ministry of Health, Labor, and Welfare, Japan.

\section{References}

1 Starkstein SE, Chemerinski E, Sabe L, Kuzis G, Petracca G, Teson A, Leiguarda R: Prospective longitudinal study of depression and anosognosia in Alzheimer's disease. Br J Psychiatry 1997;171:47-52.

-2 Vasterling JJ, Seltzer B, Watrous WE: Longitudinal assessment of deficit unawareness in Alzheimer's disease. Neuropsychiatry Neuropsychol Behav Neurol 1997;10:197-202.

-3 Salmon E, Ruby P, Perani D, Kalbe E, Laureys S, Adam S, Collette F: Two aspects of impaired consciousness in Alzheimer's disease. Prog Brain Res 2005;150:287-298.

4 Clare L, Markova I, Verhey F, Kenny G: Awareness in dementia: a review of assessment methods and measures. Aging Ment Health 2005; 9:394-413.

5 Kashiwa Y, Kitabayashi Y, Narumoto J, Nakamura K, Ueda H, Fukui K: Anosognosia in Alzheimer's disease: association with patient characteristics, psychiatric symptoms and cognitive deficits. Psychiatry Clin Neurosci 2005;59:697-704.

-6 Al-Aloucy MJ, Cotteret R, Thomas P, Volteau M, Benmaou I, Dalla Barba G: Unawareness of memory impairment and behavioral abnormalities in patients with Alzheimer's disease: relation to professional health care burden. J Nutr Health Aging 2011;15:356-360.

-7 Neil W, Bowie P: Carer burden in dementia - assessing the impact of behavioural and psychological symptoms via self-report questionnaire. Int J Geriatr Psychiatry 2008;23:60-64.

-8 Ballard CG, Gauthier S, Cummings JL, Brodaty H, Grossberg GT, Robert P, Lyketsos CG: Management of agitation and aggression associated with Alzheimer disease. Nat Rev Neurol 2009;5:245-255.

-9 Skovdahl K, Kihlgren AL, Kihlgren M: Different attitudes when handling aggressive behaviour in dementia narratives from two caregiver groups. Aging Ment Health 2003;7:277-286.

10 Maki Y, Amari M, Yamaguchi T, Nakaaki S, Yamaguchi H: Anosognosia: patients' distress and self-awareness of deficits in Alzheimer's disease. Am J Alzheimers Dis Other Demen 2012;27:339-345.

11 Mimura M: Memory impairment and awareness of memory deficits in early-stage Alzheimer's disease. Tohoku J Exp Med 2008;215:133-140.

-12 Maki Y, Yamaguchi T, Yamaguchi H: Symptoms of Early Dementia-11 Questionnaire (SED-11Q): a brief informant-operated screening for dementia. Dement Geriatr Cogn Disord Extra 2013;3:131-142.

13 Morris JC: The Clinical Dementia Rating (CDR): current version and scoring rules. Neurology 1993;43:24122414.

14 Dubois B, Feldman HH, Jacova C, Dekosky ST, Barberger-Gateau P, Cummings J, Delacourte A, Galasko D, Gauthier S, Jicha G, Meguro K, O’Brien J, Pasquier F, Robert P, Rossor M, Salloway S, Stern Y, Visser PJ, Scheltens P: Research criteria for the diagnosis of Alzheimer's disease: revising the NINCDS-ADRDA criteria. Lancet Neurol 2007;6:734-746. 
Early Dementia-11 Questionnaire (SED-11Q)

15 Grundman M, Petersen RC, Ferris SH, Thomas RG, Aisen PS, Bennett DA, Foster NL, Jack CR Jr, Galasko DR, Doody R, Kaye J, Sano M, Mohs R, Gauthier S, Kim HT, Jin S, Schultz AN, Schafer K, Mulnard R, van Dyck CH, Mintzer J, Zamrini EY, Cahn-Weiner D, Thal LJ: Mild cognitive impairment can be distinguished from Alzheimer disease and normal aging for clinical trials. Arch Neurol 2004;61:59-66.

16 Reisberg B, Ferris SH, Kluger A, Franssen E, Wegiel J, de Leon MJ: Mild cognitive impairment (MCI): a historical perspective. Int Psychogeriatr 2008;20:18-31.

17 Winblad B, Palmer K, Kivipelto M, Jelic V, Fratiglioni L, Wahlund LO, Nordberg A, Backman L, Albert M, Almkvist O, Arai H, Basun H, Blennow K, de Leon M, DeCarli C, Erkinjuntti T, Giacobini E, Graff C, Hardy J, Jack C, Jorm A, Ritchie K, van Duijn C, Visser P, Petersen RC: Mild cognitive impairment - beyond controversies, towards a consensus: report of the International Working Group on Mild Cognitive Impairment. J Intern Med 2004;256: 240-246.

18 Baumgarten M, Becker R, Gauthier S: Validity and reliability of the dementia behavior disturbance scale. J Am Geriatr Soc 1990;38:221-226.

19 Yesavage JA, Brink TL, Rose TL, Lum O, Huang V, Adey M, Leirer VO: Development and validation of a geriatric depression screening scale: a preliminary report. J Psychiatr Res 1982;17:37-49.

20 Migliorelli R, Teson A, Sabe L, Petracca G, Petracchi M, Leiguarda R, Starkstein SE: Anosognosia in Alzheimer's disease: a study of associated factors. J Neuropsychiatry Clin Neurosci 1995;7:338-344.

-21 Sato J, Nakaaki S, Murata Y, Shinagawa Y, Matsui T, Hongo J, Tatsumi H, Akechi T, Furukawa TA: Two dimensions of anosognosia in patients with Alzheimer's disease: reliability and validity of the Japanese version of the Anosognosia Questionnaire for Dementia (AQ-D). Psychiatry Clin Neurosci 2007;61:672-677.

22 Kalbe E, Salmon E, Perani D, Holthoff V, Sorbi S, Elsner A, Weisenbach S, Brand M, Lenz O, Kessler J, Luedecke S, Ortelli P, Herholz K: Anosognosia in very mild Alzheimer's disease but not in mild cognitive impairment. Dement Geriatr Cogn Disord 2005;19:349-356.

23 Onor ML, Trevisiol M, Negro C, Aguglia E: Different perception of cognitive impairment, behavioral disturbances, and functional disabilities between persons with mild cognitive impairment and mild Alzheimer's disease and their caregivers. Am J Alzheimers Dis Other Demen 2006;21:333-338.

-24 Orfei MD, Varsi AE, Blundo C, Celia E, Casini AR, Caltagirone C, Spalletta G: Anosognosia in mild cognitive impairment and mild Alzheimer's disease: frequency and neuropsychological correlates. Am J Geriatr Psychiatry 2010;18:1133-1140.

25 Kitwood T, Bredin K: Towards a theory of dementia care: personhood and well-being. Ageing Soc 1992;12: 269-287.

26 Carr DB, Gray S, Baty J, Morris JC: The value of informant versus individual's complaints of memory impairment in early dementia. Neurology 2000;55:1724-1726.

27 Pearman A, Storandt M: Predictors of subjective memory in older adults. J Gerontol B Psychol Sci Soc Sci 2004; 59:P4-P6. 